\title{
Complete Achilles Tenotomy: A New Improved Experimental Surgical Technique in Rats
}

\section{Kelly Biancardini Gomes Barbato ${ }^{1 *}$, Guilherme de Almeida ${ }^{2}$, João da Costa ${ }^{2}$, Libardo Rodriguez ${ }^{2}$, Clara Raposo3, Hanna Dias ${ }^{3}$, Renata Paiva ${ }^{3}$, Liszt Palmeira de Oliveira ${ }^{2}$, Jorge Carvalho ${ }^{4}$}

${ }^{1}$ Clinical and Experimental Pathophysiology Postgraduate Program, School of Medicine, State University of Rio de Janeiro, Rio de Janeiro, Brazil ${ }^{2}$ Department of Surgical Specialties, School of Medicine, State University of Rio de Janeiro, Rio de Janeiro, Brazil ${ }^{3}$ School of Medicine, State University of Rio de Janeiro, Rio de Janeiro, Brazil

${ }^{4}$ Department of Histology and Embriology, Roberto Alcântara Gomes Institute of Biology, State University of Rio de Janeiro, Rio de Janeiro, Brazil

Email: *kelbiancardini@gmail.com, drguilhermealmeida@gmail.com,jmctpg@yahoo.com.br, netob44@hotmail.com, clara_raposo@yahoo.com.br, hanna.dias@yahoo.com.br, renatayres@yahoo.com.br, lisztpalmeira@yahoo.com.br, carvalho@uerj.br

How to cite this paper: Barbato, K.B.G., de Almeida, G., da Costa, J., Rodriguez, L., Raposo, C., Dias, H., Paiva, R., de Oliveira, L.P. and Carvalho, J. (2018) Complete Achilles Tenotomy: A New Improved Experimental Surgical Technique in Rats. Open Journal of Animal Sciences, 8, 1-11. https://doi.org/10.4236/ojas.2018.81001

Received: September 3, 2017

Accepted: November 28, 2017

Published: December 1, 2017

Copyright (c) 2018 by authors and Scientific Research Publishing Inc. This work is licensed under the Creative Commons Attribution International License (CC BY 4.0).

http://creativecommons.org/licenses/by/4.0/ (c) (i) Open Access

\begin{abstract}
Rupture of the Achilles tendon is one of the most frequent tendon injuries in humans. However, there is no standard surgical technique thus far to reproduce complete rupture of this tendon in rats. Surgical procedures were performed in Wistar rats under light microscopy, with posterior longitudinal incision and preservation of the plantaris tendon. The animals were sacrificed on $2^{\text {nd }}$ and $8^{\text {th }}$ postoperative week and we used hematoxilin and eosin, picrosirius-red and Weigert's resorcin-fuchsin to observe general tendon healing. The mean operative time was one minute and 24 seconds. Histological studies showed cellular proliferation and fibrillogenesis at two weeks, with decreased amounts of cellularity and elastic fibers at the $8^{\text {th }}$ week, besides changes in structural organization of collagen fibers. The complete Achilles tenotomy in rats, was improved under light microscopy and sparing the plantaris tendon. This surgical technique was simple and quick, showed signs of normal healing process, could be easily reproducible, and triggered translational researches in this area.
\end{abstract}

\section{Keywords}

Achilles Tendon Rupture, Animal Experimentation, Wound Healing, Collagen, Elastic Tissue 


\section{Introduction}

Rupture of the Achilles tendon in humans is one of the most frequent tendon injuries found in clinical practice and its incidence has increased in recent years [1]. This increase can be attributed to the rising number of middle-aged and elderly practitioners of sports activities, so-called "weekend athletes" [2], as well as the increased participation in professional sports [3].

Several experimental models have been used for the study of Achilles tendon injury, involving different animal species, including dogs, horses, goats, rabbits, monkeys, sheep, rats and mice [4] [5] [6] [7] [8]. Rats and mice share several advantages over other species used as animal models of tendon injuries. These small rodents have maintenance costs that are ten times lower than those for rabbits. They also have short pregnancies, rapid growth and multiple offspring, as well as behavior that tolerate human handling [9]. In terms of equivalence, rats show similar limb anatomy and their genome is $80 \%$ to $90 \%$ homologous to that of humans [10] [11].

Experimental models of Achilles tenotomy in rats described in the medical literature vary regarding the extent (partial or complete), the surgical approach (percutaneous or open) and the route of access (lateral or posterior). Little attention is typically given to the plantaris tendon, which is much more developed in rats [12] and is able to carry a substantial load during weight bearing [13]. The aim of this paper is to describe an improved experimental technique for complete Achilles tenotomy in rats, with plantaris tendon sparing, performed under light microscopy.

\section{Materials and Methods}

The authors used 12 male Wistar rats that were three months old and weighed 300 grams, on average. All animals came from the Laboratory of Experimental Surgery of the Faculty of Medical Sciences, State University of Rio de Janeiro. This study was approved by the Ethics Committee for the Care and Use of Experimental Animals of the Roberto Alcântara Gomes Institute of Biology at the State University of Rio de Janeiro. Surgical procedures were performed at the Laboratory of Experimental Microsurgery, Department of Orthopedics, at Pedro Ernesto University Hospital of the State University of Rio de Janeiro. Each rat underwent complete Achilles tenotomy of the right posterior limb, preserving the plantaris tendon. The operations were performed with the aid of light microscopy under general anesthesia with a 30 to $50 \mathrm{mg} / \mathrm{kg}$ intraperitoneal injection of thiopental. For the anesthetic procedure, the ventral region of the rat was divided into four quadrants, and the injection of anesthetic was performed in the lower right quadrant, with an entry angle of 45 degrees to the skin. Adequate anesthetic level was verified by the reduction of corneal and flexor reflexes.

Surgical instruments were autoclaved and available in advance at the beginning of each procedure (Figure 1). "Tips-only" technique was used, with non-sterile gloves [14]. Between each procedure, the tips of the instruments were 


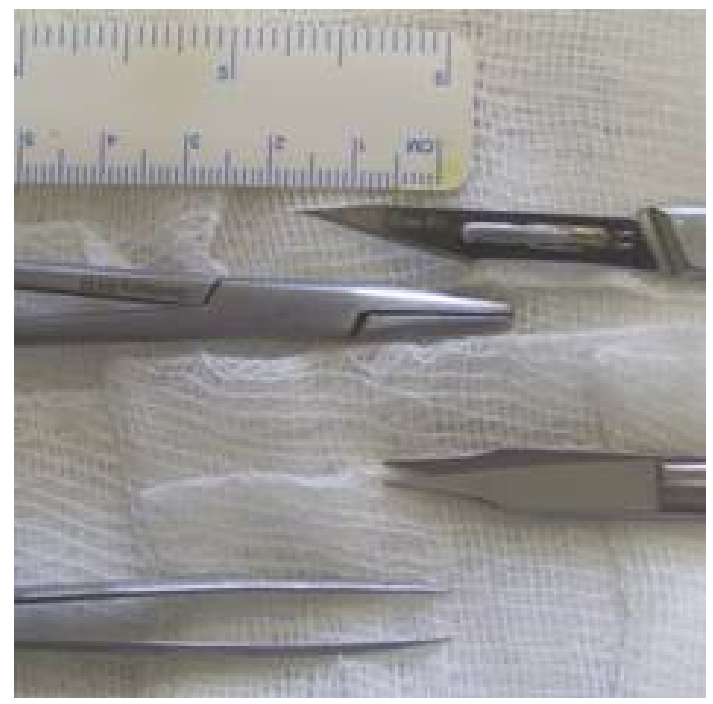

Figure 1. Surgical instruments used for Achilles tenotomy.

washed with $70 \%$ alcohol. All surgical procedures were performed by the same surgeon. The surgical time was recorded, from initial skin incision to final suture. No antibiotic prophylaxis was used.

\subsection{Surgical Technique-Complete Rupture of the Achilles Tendon}

\subsubsection{First Step}

Antisepsis of the right hind leg of rats was performed with 70\% alcohol, followed by protection with sterile gauze, without shaving. The paw of the animal was stabilized in slight dorsiflexion by an assistant (Figure 2).

\subsubsection{Second Step}

Under 10× magnification, a posterior longitudinal incision, approximately five millimeters in length, was made towards the proximal direction with a No. 11 scalpel blade, starting five millimeters proximal to the posterior calcaneal tuberosity of the right paw of the animal (Figure 3).

\subsubsection{Third Step}

The plantaris tendon was recognized and retracted medially, which allowed recognition of the space between the Achilles tendon and the plantaris tendon. The Achilles tendon was individualized (Figure 4).

\subsubsection{Fourth Step}

A transverse cut in the middle of the Achilles tendon was created seven millimeters from the calcaneal tuberosity, lateral to the plantaris tendon, which was carefully preserved. After tenotomy, retraction of the proximal stump of the tendon was observed during passive foot dorsiflexion (Figure 5).

\subsubsection{Fifth Step}

The skin incision was sewed with non-absorbable sutures (4 - 0 nylon monofilament) and cleaned again with $70 \%$ alcohol. 


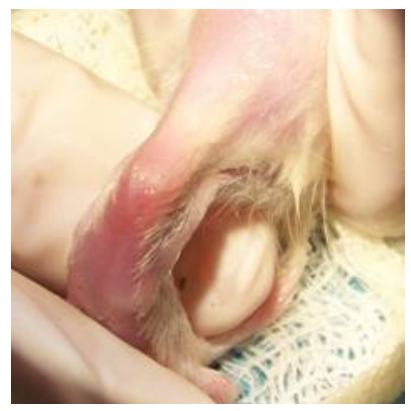

Figure 2. Right posterior limb stabilized in slight dorsiflexion.

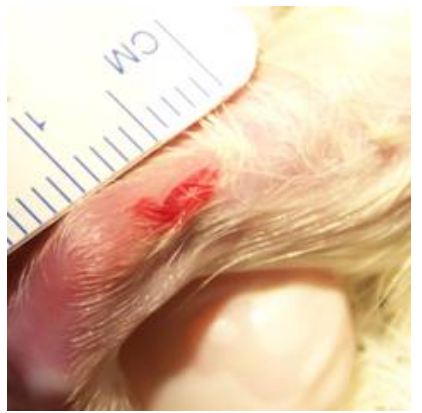

Figure 3. Posterior longitudinal incision.

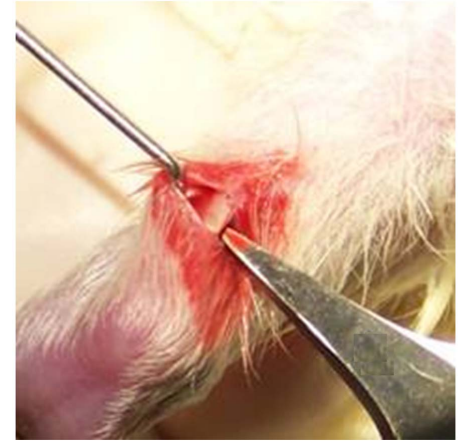

(a)

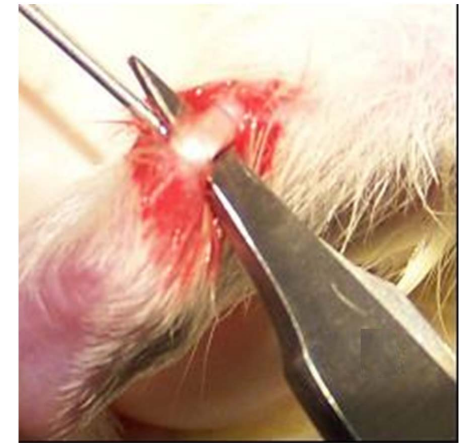

(b)

Figure 4. (a) Identification of the space between the plantaris tendon medially and the Achilles tendon laterally; (b) Individualization of the Achilles tendon.

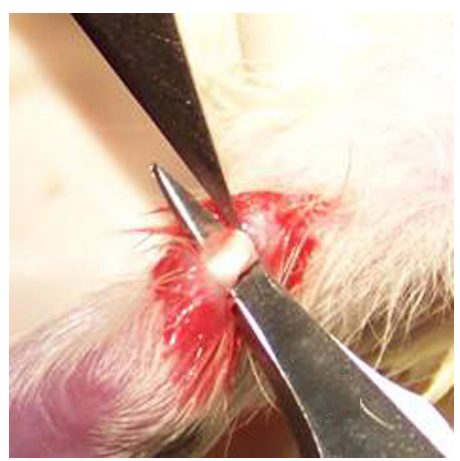

(a)

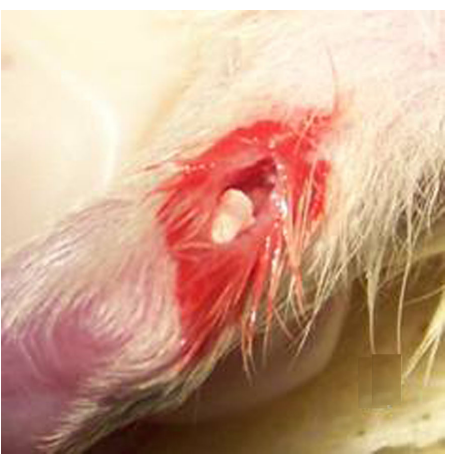

(b)

Figure 5. (a) A transverse cut of the Achilles tendon; (b) Retraction of the proximal stump during passive foot dorsiflexion. 


\subsection{Postoperative Care}

After surgery, the rats were kept in collective cages with four animals in each and fed with food and water ad libitum with ambient temperature $\left(21^{\circ} \mathrm{C} \pm 2^{\circ} \mathrm{C}\right)$ and humidity $(60 \% \pm 10 \%)$ monitored, with $15 \mathrm{~min} / \mathrm{h}$ ventilation. Animals' sacrifices happened on $2^{\text {nd }}$ and $8^{\text {th }}$ postoperative week, six rats in each time point, and had the right Achilles tendon dissected, fixed in a $10 \%$ formalde in solution and processed for paraffin inclusion. Afterword, we made five micrometres thick slices, and processed them to histological studies to observe general tendon healing, especially regarding collagen and elastic fibers. We used hematoxilin and eosin (HE), picrosirius-red under polarized light [15] and Weigert's resorcin-fuchsin, preceded by $10 \%$ kalemic monopersulfate oxidation [16].

\section{Results}

The mean operative time was one minute and 24 seconds (1'24"), ranging from one minute and nine seconds (1'09") to one minute and 44 seconds (1'44"). In all cases, the animals had fully recovered from anesthesia and exhibited a return to normal behavior. All animals showed healing of the wound without skin necrosis. There was also no drainage discharge or bleeding, observed until the $8^{\text {th }}$ week after tenotomy.

Macroscopically, two weeks after operation, the tendon rupture site showed signs of healing, with a gelatinous connective tissue forming a bridge between the edges of the tendon (Figure 6).

At microscopic evaluation of tendon healing process with HE, we observed an increased cellularity two weeks after tendon rupture, while at the $8^{\text {th }}$ week, we found a relative lowering of the cellular content (Figure 7).

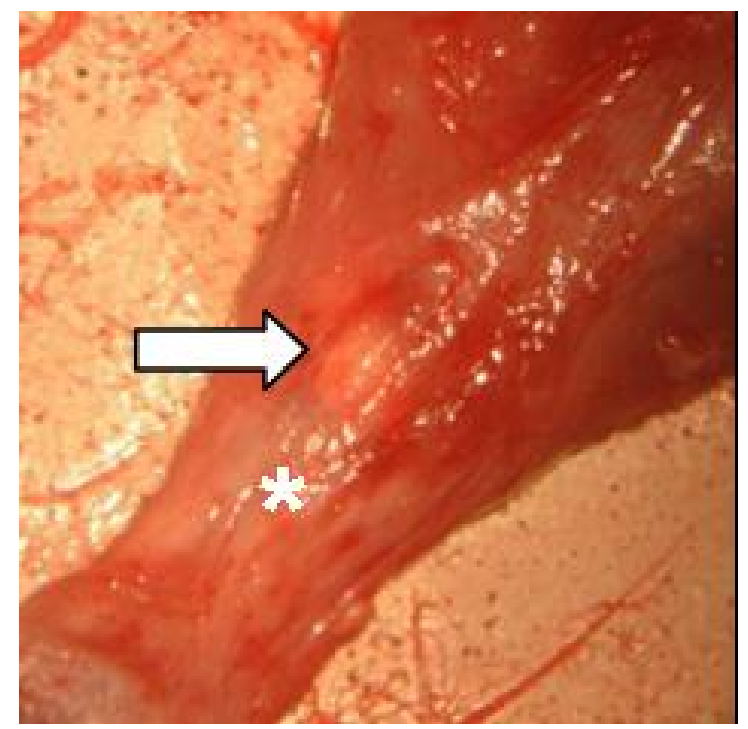

Figure 6. Macroscopic evaluation of the Achilles tendon in the $14^{\text {th }}$ day after tenotomy. It is observed retraction of the proximal stump (white arrow) of the Achilles tendon and scar tissue formation $\left(^{*}\right)$ in the space between the edges of the tendon. Image obtained with the aid of light microscope (10-fold increase). 


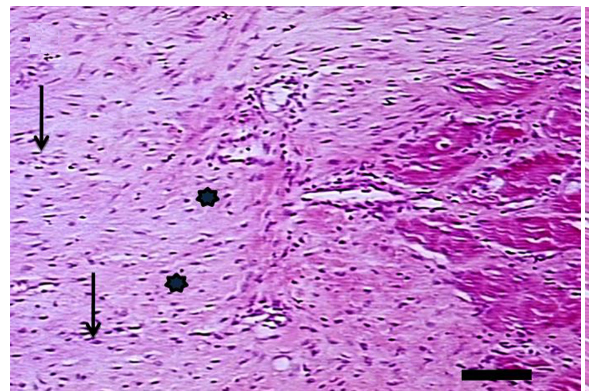

(a)

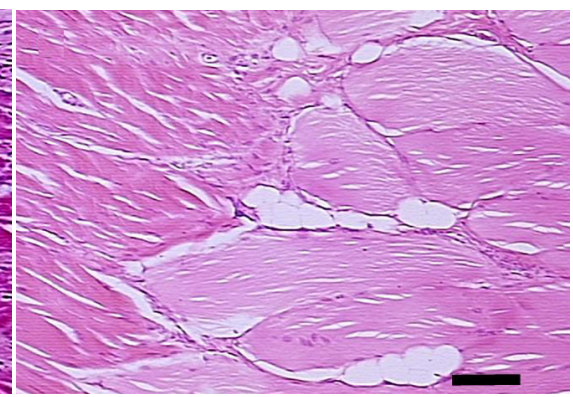

(b)

Figure 7. Microscopic aspect of a longitudinal slice of the Achilles tendon. (a) Two weeks after tenotomy. We see extracellular matrix $\left({ }^{*}\right)$, rich in collagen fibers and with a high cellular content (black arrows); (b) At the $8^{\text {th }}$ week after tenotomy. We see relative decrease in the cellularity of the extracellular matrix. Technique: HE. Bar: $100 \mu \mathrm{m}$.

The picrosirius-red technique, under polarized light, showed high amounts of red thick fibrils, two weeks after tendon rupture, suggestive of type I collagen. At the $8^{\text {th }}$ week, there was a shift to higher amounts of thinner collagen fibrils, slight yellow-green colored, probably type III collagen. At musculotendinous junction, two weeks after tendon rupture, we observed mixed contents of thin yellow-green colored collagen fibrils between thicker red colored collagen fibrils. We did not find this aspect at the intermediate portion of the tendon scar tissue at this time point (Figure 8).

We observed a high expression of elastic fibers two weeks after tendon rupture, as showed by Weigert's resorcin-fuchsin technique. There was a relative reduction of the elastic fiber contents at the $8^{\text {th }}$ week, with the same technique (Figure 9).

\section{Discussion}

In the 1930s, several reports [17] attempted to experimentally induce Achilles tendon rupture in rabbits using traction and crushing. Since then, several studies in the literature have attempted to elucidate the process of tendon regeneration through experimental models of injury to the Achilles tendon. However, there is no standard surgical technique thus far to reproduce complete rupture of the Achilles tendon in rats. Several studies have used experimental models of injury to the Achilles tendon in rats, with variation in the type of injury (complete or partial section, draw, perforations, traction or crushing), the surgical approach (percutaneous or open) and the route of access (lateral or posterior incision) [2] [13] [18] [19] [20]. Ehrlich et al. [21] and Arruda et al. [22] described a technique for complete tenotomy that is easily reproduced in rats, but without description of the plantaris tendon or exact localization of the tendon section. McGaw [8] described tenotomy in an unusual place, at the muscular insertion of the Achilles tendon, without detailing the surgical procedure itself.

The surgical anatomy of the rat, although similar to that of the human, has some characteristics that are typical of this species and that should be taken into 


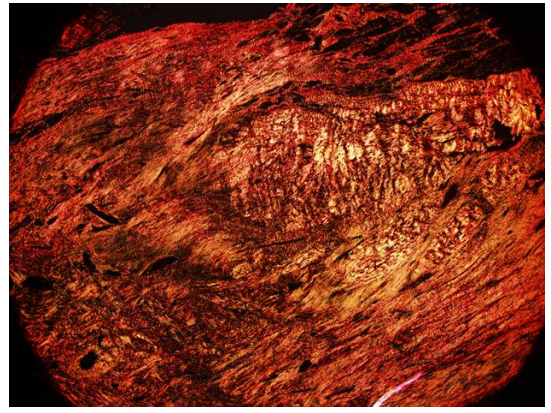

(a)

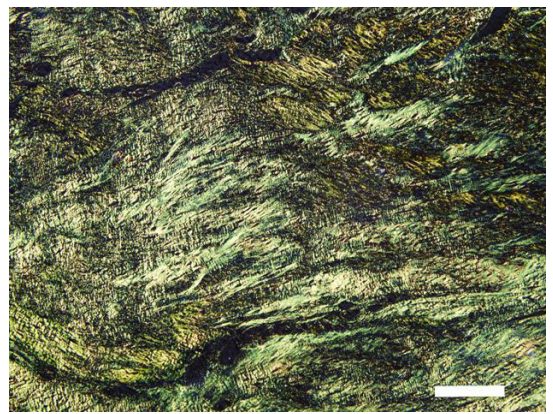

(c)

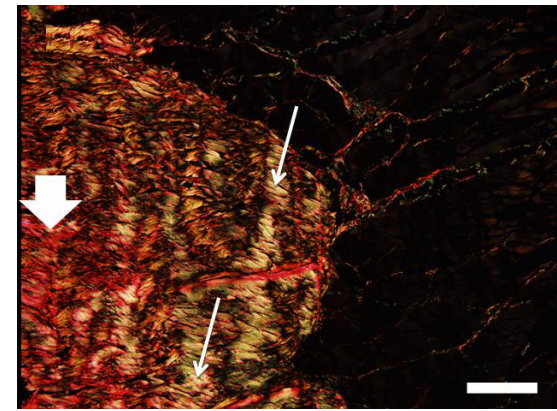

(b)

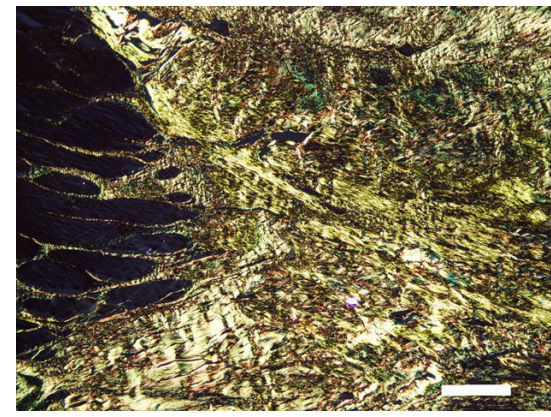

(d)

Figure 8. Microscopic aspect of a longitudinal slice of the Achilles tendon. (a) Intermediate portion of the tendon, two weeks after tenotomy, showing extracellular matrix plenty of thick red collagen fibrils; (b) At the musculotendinous junction, two weeks after tenotomy, we can see thin yellow-green colored collagen fibrils (thin arrow) between thicker red colored collagen fibrils (thick arrow); (c) and (d) Intermediate portion of tendon scar tissue (c) and musculotendinous junction (d), both at $8^{\text {th }}$ week after tenotomy, showing predominance of thinner yellow-green colored collagen fibrils in the extracellular matrix. Technique: Picrosirius-red. Bar: $300 \mu \mathrm{m}$.

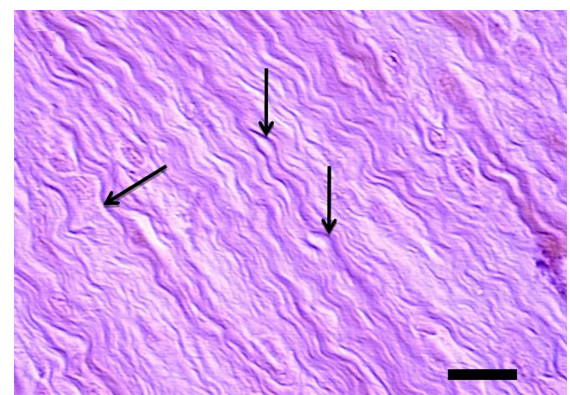

(a)

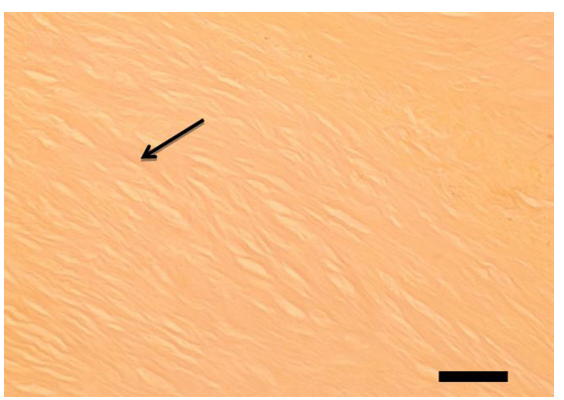

(b)

Figure 9. Microscopic aspect of a longitudinal slice of the Achilles tendon. (a) Elastic fibers (black arrows) between collagen fiber beams, at two weeks after tenotomy; (b) At the $8^{\text {th }}$ week after tenotomy, there is a reduction in the number of elastic fibers (black arrow). Technique: Weigert's resorcin-fuchsin, preceded by $10 \%$ kalemic monopersulfate oxidation. Bar: $30 \mu \mathrm{m}$.

account [23]. In our study, we found that identification of the plantaris tendon, located medially but very close to the Achilles tendon, is an important point of anatomical reference, and its identification is facilitated by the posterior access and the use of light microscopy that characterize this technique. Some authors 
[13] [24] [25], all using the same surgical technique, with lateral access to the animal's right Achilles tendon and a small longitudinal incision of two to three millimeters, performed a tendon cross-section 1.5 millimeter proximal to the calcaneal insertion. In these papers, there is also reference to the plantaris tendon, which was removed in two of these studies to simplify the biomechanical evaluation performed at the end of the experiment.

Although we verified that the identification and individualization of the rat Achilles tendon are relatively difficult when using the naked eye, we did not find any reference in the literature to the use of accessories for image magnification (loupe or operating microscope). Furthermore, some studies refer to the need for careful preservation of peritendinous structures, especially of the arterial supply, in open tenotomy of the Achilles tendon. Considering that the blood supply to the Achilles tendon originates from the musculotendinous junction, bone insertion and multiple vessels of mesotendon [26], we suggest the open approach and use of the surgical microscope to minimize damage to these structures.

The cell density could be elevated by six to sevenfold during tendon healing [27]. Our microscopic findings describe the tendon healing process after a complete rupture, showing a trend to cellular proliferation and fibrilogenesis two weeks after injury. At the $8^{\text {th }}$ week, we found decreased cellularity with high amount of the extracellular matrix, rich in collagen fibers.

It is known that type I collagen represents $90 \%$ of the collagen fibers in normal tendons [28] and ruptured Achilles tendons show increased amounts of type III collagen [29], as found at the tendon healing in our study. The substitution of this stronger type I collagen fibrils, for those thinner and weaker type III collagen fibrils, seems to begin at the musculotendinous junction, as showed by the picrosirius-red technique, under polarized light, two weeks after tendon rupture. Maffulli $\mathrm{N}$ et al. [30] also described tendon changes in humans localized in the macroscopic intact proximal and distal tendon portion and not only at the site of rupture.

Beyond that, we observed a high number of elastic fibers two weeks after tendon rupture, which may represent the beginning of the healing remodelative phase. This increase in fibers of the elastic system content may represent a secondary hole to collagen fibers function, mainly in the tendon resistance to tension, considering that oxitalanics fibers of the elastic system are rich in fibrilin, found in tissues subjected to high tensile stress [31] [32] [33].

Achilles tendon ruptures are common and devastating injuries in humans [34]. Despite improved knowledge of Achilles tendon pathology, the optimal treatment and the best rehabilitation protocol after an acute rupture remain a matter of controversy in orthopaedic and sports medicine [35]. In experimental studies on animal tendons, partial or complete surgical tenotomy is the most commonly used method for inducing injury [36] and these models appear useful for investigating the effect of therapies in acute tendon injuries [20]. 


\section{Conclusion}

The improved surgical technique described, for complete tenotomy of the Achilles tendon in rats, sparing the plantaris tendon with the aid of light microscopy, is simple and quickly done. It shows signs of normal healing process and could be used as an easily reproducible model of experimental tendon lesion, which could encourage translational researches about this common tendon injury in humans.

\section{Acknowledgements}

These authors have received research funding from Faperj-process numbers E-26/102.106/2009 (Scientific Initiation Fellowship) and E-26/110.871/2009 (Aid Research), but there was no conflict of interest in connection with the submitted article.

\section{References}

[1] Järvinen, T.A., Kannus P., Paavola M., Järvinen T.L., Józsa, L. and Järvinen, M. (2001) Achilles Tendon Injuries. Current Opinion in Rheumatology, 13, 150-155. https://doi.org/10.1097/00002281-200103000-00009

[2] Marsolais, D., Cote, C.H. and Frenette, J. (2003) Nonsteroidal Anti-Inflammatory Drug Reduces Neutrophil and Macrophage Accumulation But Does Not Improve Tendon Regeneration. Laboratory Investigation, 83, 991-999. https://doi.org/10.1097/01.LAB.0000078688.07696.AC

[3] Hess, G.W. (2010) Achilles Tend on Rupture: A Review of Etiology, Population, Anatomy, Risk Factors, and Injury Prevention. Foot \& Ankle Specialist, 3, 29-32. https://doi.org/10.1177/1938640009355191

[4] Cohen, M.S., Turner, T.M. and Urban, R.M. (2006) Effects of Implant Material and Plate Design on Tendon Function and Morphology. Clinical Orthopaedics, 445, 81-90.

[5] Dahlgren, L.A., van der Meulen, M.C., Bertram, J.E., Starrak, G.S. and Nixon, A.J. (2002) Insulin-Like Growth Factor-I Improves Cellular and Molecular Aspects of Healing in a Collagenase-Induced Model of Flexor Tendinitis. Journal of Orthopaedic Research, 20, 910-919. https://doi.org/10.1016/S0736-0266(02)00009-8

[6] Fealy, S., Rodeo, S.A., MacGillivray, J.D., Nixon, A.J., Adler, R.S. and Warren, R.F. (2006) Biomechanical Evaluation of the Relation between Number of Suture Anchors and Strength of the Bone-Tendon Interface in a Goat Rotator Cuff Model. Arthroscopy, 22, 595-602. https://doi.org/10.1016/j.arthro.2006.03.008

[7] Giordano, V., Pallottino, A.B., Almeida, R.N., Giordano, M.N., Amaral, N.P., Apfel, M.I.R. and Bastos, J.S.A. (2004) Estudo experimental comparativo de duas técnicas de sutura para reparo do tendão de Aquiles: análises bioquímica, histológica e mecânica. Revista Brasileira de Ortopedia, 39, 590-600.

[8] McGaw, W.T. (1986) The Effect of Tension on Collagen Remodelling by Fibroblasts: A Stereological Ultrastructural Study. Connective Tissue Research, 14, 229-235. https://doi.org/10.3109/03008208609014263

[9] Warden, S.J. (2007) Animal Models for the Study of Tendinopathy. British Journal of Sports Medicine, 41, 232-240. https://doi.org/10.1136/bjsm.2006.032342

[10] Abbott, A. (2004) Laboratory Animals: The Renaissance Rat. Nature, 428, 464-466. 
https://doi.org/10.1038/428464a

[11] Gibbs, R.A., Weinstock, G.M., Metzker, M.I., et al. (2004) Genome Sequence of the Brown Norway Rat Yields Insights into Mammalian Evolution. Nature, 428, 493-521. https://doi.org/10.1038/nature02426

[12] Mrázková, O. and Dylevský, I. (1971) The Tensor Aponeurosis Plantaris-A New Muscle in the Rat Limb. Folia Morphologica (Praha), 19, 352-357.

[13] Dimmen, S., Lars, E. and Jan, E. (2009) Negative Effects of Parecoxib and Indomethacin on Tendon Healing: An Experimental Study in Rats. Knee Surgery, Sports Traumatology, Arthroscopy, 17, 835-839. https://doi.org/10.1007/s00167-009-0763-7

[14] Hoogstraten-Miller, S.L. and Brown, P.A. (2008) Techniques in Aseptic Rodent Surgery. Current Protocols in Immunology, Chapter: Unit-1, 12-14. https://doi.org/10.1002/0471142735.im0112s82

[15] Montes, G.S. (1996) Structural Biology of the Fibres of the Collagenous and Elastic Systems. Cell Biology International, 20, 15-27. https://doi.org/10.1006/cbir.1996.0004

[16] Cotta-Pereira, G., Guerra Rodrigo, F. and Bittencourt-Sampaio, S. (1976) Oxytalan, Elaunin, and Elastic Fibers in the Human Skin. Journal of Investigative Dermatology, 66, 143-148. https://doi.org/10.1111/1523-1747.ep12481882

[17] McMaster, P. (1933) Tendon and Muscle Ruptures-Clinical and Experimental Studies on the Causes and Location of Subcutaneous Ruptures. The Journal of Bone and Joint Surgery, 15, 705-722.

[18] Carvalho, P.T., Silva, I.S., Reis, F.A., Belchior, A.C.G., Aydos, R.D., Facco, G.G. and Dourado, D.M. (2006) Histological Study of Tendon Healing in Malnourished Wistar Rats Treated with Ultrasound Therapy. Acta Cirúrgica Brasileira, 21, 13-17. https://doi.org/10.1590/S0102-86502006001000004

[19] Godbout, C.H., Oliver, A.N. and Frenette, J. (2006) Early Voluntary Exercise Does Not Promote Healing in a Rat Model of Achilles Tend on Injury. Journal of Applied Physiology, 101, 1720-1726. https://doi.org/10.1152/japplphysiol.00301.2006

[20] Nicodemo, M.C., Neves, L.R., Aguiar, J.C., Brito, F.S., Ferreira, I., Sant'Anna, L.B., Raniero, L.J., Martins, R.Á., Barja, P.R. and Arisawa, E.A. (2017) Amniotic Membrane as an Option for Treatment of Acute Achilles Tendon Injury in Rats. Acta Cirúrgica Brasileira, 32, 125-139. https://doi.org/10.1590/s0102-865020170205

[21] Ehrlich, H.P., Lambert, P.A., Saggers, G.C., Myers, R.L. and Hauck, R.M. (2005) Dynamic Changes Appearing in Collagen Fibers during intrinsic Tendon Repair. Annals of Plastic Surgery, 54, 201-206. https://doi.org/10.1097/01.sap.0000141380.52782.db

[22] Arruda, E.R.B., Rodrigues, N.C., Taciro, C. and Parizotto, N.A. (2007) Influência de diferentes comprimentos de onda da laserterapia de baixa intensidade na regeneração tendínea do rato após tenotomia. Brazilian Journal of Physical Therapy, 11, 283-288. https://doi.org/10.1590/S1413-35552007000400007

[23] Wang, L.C. and Kernell, D. (2001) Fibre Type Regionalisation in Lower Hindlimb Muscles of Rabbit, Rat and Mouse: A Comparative Study. Journal of Anatomy, 199, 631-643. https://doi.org/10.1046/j.1469-7580.2001.19960631.x

[24] Forslund, C., Bylander, B. and Aspenberg, P. (2003) Indomethacin and Celecoxib Improve Tendon Healing in Rats. Acta Orthopaedica Scandinavica, 74, 465-469. https://doi.org/10.1080/00016470310017802

[25] Virchenko, O., Skoglund, B. and Aspenberg, P. (2004) Parecoxib Impairs Early 
Tendon Repair but Improves Later Remodeling. The American Journal of Sports Medicine, 32, 1743-1747. https://doi.org/10.1177/0363546504263403

[26] Doral, M.N., Alam, M., Bozkurt, M., Turhan, E., Atay, O.A., Dönmez, G. and Maffulli, N. (2010) Functional Anatomy of the Achilles Tendon. Knee Surgery, Sports Traumatology, Arthroscopy, 18, 638-643.

https://doi.org/10.1007/s00167-010-1083-7

[27] Lui, P.P., Cheuk, Y.C., Hung, L.K., Fu, S.C. and Chan, K.M. (2007) Increased Apoptosis at the Late Stage of Tendon Healing. Wound Repair and Regeneration, 15, 702-707. https://doi.org/10.1111/j.1524-475X.2007.00276.x

[28] Tsai, W.C., Hsu, C.C., Chou, S.W., Chung, C.Y., Chen, J. and Pang, J.H. (2007) Effects of Celecoxib on Migration, Proliferation and Collagen Expression of Tendon Cells. Connective Tissue Research, 48, 46-51. https://doi.org/10.1080/03008200601071295

[29] Coombs, R.R.H., Klenerman, L., Narcisi, P., Nichols, A. and Pope, F.M. (1980) Collagen Typing in Achilles Tendon Rupture. The Journal of Bone and Joint Surgery, 62-B, 258.

[30] Maffulli, N., Longo, U.G., Maffulli, G.D., Rabitti, C., Khanna, A. and Denaro, D. (2011) Marked Pathological Changes Proximal and Distal to the Site of Rupture in Acute Achilles Tendon Ruptures. Knee Surgery, Sports Traumatology, Arthroscopy, 19, 680-687. https://doi.org/10.1007/s00167-010-1193-2

[31] Cotta-Pereira, G. and Iruela-Arispe, M.L. (1989) Extracellular Matrix: Functional Significance of Oxytalan, Elaunin and Elastic Fibers. Progress in Clinical and Biological Research, 295, 101-107.

[32] Fullmer, H.M. (1960) A Comparative Histochemical Study of Elastic, Pre-Elastic and Oxytalan Connective Tissue Fibers. Journal of Histochemistry \& Cytochemistry, 8, 290-295. https://doi.org/10.1177/8.4.290

[33] Kielty, C.M., Sherratt, M.J. and Shuttleworth, C.A. (2002) Elastic Fibres. Journal of Cell Science, 115, 2817-2828.

[34] Freedman, B.R., Gordon, J.A., Bhatt, P.R., Pardes, A.M., Thomas, S.J., Sarver, J.J., Riggin, C.N., Tucker, J.J., Williams, A.W., Zanes, R.C., Hast, M.W., Farber, D.C., Silbernagel, K.G. and Soslowsky, L.J. (2016) Nonsurgical Treatment and Early Return to Activity Leads to Improved Achilles Tendon Fatigue Mechanics and Functional Outcomes during Early Healing in an Animal Model. Journal of Orthopaedic Research, 34, 2172-2180. https://doi.org/10.1002/jor.23253

[35] Spennacchio, P., Vascellari, A., Cucchi, D., Canata, G.L. and Randelli, P. (2016) Outcome Evaluation after Achilles Tendon Ruptures. A Review of the Literature. Joints, 4, 52-61. https://doi.org/10.11138/jts/2016.4.1.052

[36] Joensen, J., Gjerdet, N.R., Hummelsund, S., Iversen, V., Lopes-Martins, R.A.B. and Bjordal, J.M. (2012) An Experimental Study of Low-Level Laser Therapy in Rat Achilles Tendon Injury. Lasers in Medical Science, 27, 103-111. https://doi.org/10.1007/s10103-011-0925-y 